\title{
"Mixed" subjective class identity: a new interpretation of Chinese class identity
}

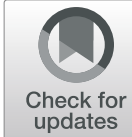

Qi Xu(10)

\author{
Correspondence: xuqi@nju.edu.cn \\ School of Social and Behavioral \\ Sciences, Nanjing University, Xianlin \\ Avenue 163, Qixia District, Nanjing \\ 210023, Jiangsu Province, China
}

\begin{abstract}
This article investigates factors influencing the subjective class identity of Chinese people and the bias of this identity using data from the Chinese General Social Survey in 2010 and 2013. In contrast with previous studies that have only focused on the social status of the respondents, this paper introduces the concept of "mixed" class identity and finds that (1) the social statuses of a person's spouse and parents can also affect subjective class identity and its bias, in addition to the social status of the respondents themselves; (2) the social status of parents has a stronger effect on children who are younger and who co-reside with parents, and the effect of a spouse's social status is stronger for married women than for married men; and (3) the influence of parents and a spouse's social statuses on individuals' class identity has been growing over time. This paper notes that to understand the subjective class identity of the Chinese and its change over time, sociologists should focus on family as the basic unit of analysis, fully consider the heterogeneity effect of different factors affecting the class identity of different social groups and situate the analysis within the context of China's unique modernization process.
\end{abstract}

Keywords: Subjective class identity, Class identity bias, Objective social status, Spouse effect, Parent effect

\section{Introduction}

Since the reform and opening-up in 1978, China has entered what Polanyi described as a period of "great transformation" under the influence of economic transformation and institutional transition (Wang 2012). The emerging social strata during the transition period in China are undoubtedly of most interest to researchers of social stratification. At the inception of the reform and opening-up period, scholars focused on the objective processes of socioeconomic attainment of education, income, and occupational statuses ( $\mathrm{Li}$, 2008a; Bian 2002). It has not been until recently that an increasing number of scholars have begun to focus on the attainment of subjective social status such as class identity or class consciousness. A large number of studies have found that the Chinese subjective class identity differs from the "middle-class identity" of Western societies and tends to be downwardly biased (Bian and Lu 2002; Dong 2007; Gao 2013; Feng 2011; Li 2003; Liu 2001). Moreover, contrary to the classical "status determinism" model, many studies have found that objective socioeconomic status indicators such as education, income, and

(c) The Author(s). 2020 Open Access This article is licensed under a Creative Commons Attribution 4.0 International License, which permits use, sharing, adaptation, distribution and reproduction in any medium or format, as long as you give appropriate credit to the original author(s) and the source, provide a link to the Creative Commons licence, and indicate if changes were made. The images or other third party material in this article are included in the article's Creative Commons licence, unless indicated otherwise in a credit line to the material. If material is not included in the article's Creative Commons licence and your intended use is not permitted by statutory regulation or exceeds the permitted use, you will need to obtain permission directly from the copyright holder. To view a copy of this licence, visit http://creativecommons.org/licenses/by/4.0/. 
occupation only explain the subjective class status of Chinese to a limited extent (Lu and Zhang 2006; Liu 2002). Thus, the deviation between the subjective class status and objective status of the Chinese is a new topic that has garnered much attention from scholars (Fan and Chen 2015; Han and Qiu 2015; Lei 2009).

There are three main theories to explain the class identity bias among Chinese and why "objective status determinism" fails. The first theory stems from the logic of "objective status determinism," arguing that there is often an inconsistency between an individual's education, income, and occupational statuses in modern society, which places people in multiple layers of overlapping social groups, thus blurring their subjective class identity (Hodge and Treiman 1968; Hout 2008). The second theory emphasizes the impact of an individual's "class trajectory" on his or her current class identity (Wright and Shin 1988) and argues that individuals evaluate their current status by combining their "past" and "present" social statuses. Therefore, in the context of dramatic social change, a person's class status is often in a state of flux, and the relative changes in one's status or one's subjective perception of the social mobility process can have a significant impact on individuals' subjective evaluation of their current social status (Liu 2002; Fan and Chen 2015). Last, the third theory stems from the "reference group" theory, which argues that individuals' perceptions of their social status are acquired in reference to the social statuses of others. Because social networks are formed selectively, individuals and their reference groups are often homogenous to some extent, which makes people perceive themselves as being in the middle of the specific class (Kelley and Evans 1995). Liu (2001) proposed the concept of "relative deprivation" based on this theory, arguing that the degree of the benefit obtained by different classes or groups varies greatly in rapid social transition, which relatively deprives some people in terms of socioeconomic status or life opportunities, and individuals in a state of relative deprivation tend to underestimate their social class status (Fan and Chen 2015).

The three theories have extended the classical "objective status determinism" theory and simultaneously established an important basis to understand Chinese people's class identity and the reasons for deviations from individuals' objective classes. However, as with the classical "objective status determinism" theory, all three theories set a person's socioeconomic status as the key explanatory variable. In other words, all the theories and the "status determinism" assume that subjective class identity can be understood simply through the objective social status of the individuals (no matter whether those are measured at present, in the past, or relative to others). This assumption does not necessarily hold.

As it is well known, most individuals have families, both in China and Western societies. In addition to one's education, income, and occupational status, an individual's life chances are influenced to a large extent by other family members, such as one's spouse, parents, and other family members. Thus, in addition to the individual himself or herself, the social statuses of one's family members are likely to be important sources of how one constructs one's subjective class identity. In Western countries where the nuclear family is predominant, some scholars have paid attention to the important influence of the social status of the spouse on one's class identity (Davies and Robinson 1988). In a country with a robust extended-family tradition, such as China, the individual's family of origin (or parents), in addition to the spouse, may also be important in assessing one's own class identity. Along these lines, I propose the concept of a "mixed" subjective class identity to distinguish it from the previous tradition of focusing mostly 
on individuals themselves. Through this concept, this paper attempts to propose a new analytical perspective for studying the class identity of the Chinese people and provide a new theoretical explanation for the formation of their class identity bias.

\section{Theoretical review and research hypothesis}

\section{The effect of spouses}

From a theoretical point of view, the concept of "mixed" subjective class identity can be traced back to research on women's class status and identity by Western scholars. Historically, women's labor force participation has been low in Western countries. Influenced by the traditional gender division of labor, classical social stratification studies have largely ignored women as a result. However, with the rise of the feminist movement in the West since the 1970s and the increase in women's labor force participation, the question of women's social class status attainment has become an important issue for social stratification theorists.

Goldthorpe, a pioneering neo-Weberian stratification scholar, published a theoretical article, "Women and Class Analysis" (Goldthorpe 1983), which emphasizes "family" as the basic unit of analysis in studying social stratification. In Goldthorpe's view, the social status of a family is mainly determined by the status of the male head of the family (Goldthorpe 1983). In other words, women do not have an independent social class perception, and their husbands' social status largely influences women's perceptions of their social class identity.

Goldthorpe's traditional view of women's social status has been widely controversial (Baxter 1994), and while some studies have supported his view (Velsor and Beeghley 1979), many scholars, especially feminist scholars, have harshly criticized it (Stanworth 1984). Whether Goldthorpe is correct is beyond the scope of this study. However, an essential contribution of this viewpoint lies in proposing a family-based analytical perspective and in pointing out the vital role of the spouse in determining one's subjective class identity. Inspired by Goldthorpe, many Western scholars began to examine the relative influence of the social status of the respondents themselves on the social status of their spouses in determining one's class identity, and the analysis was applied to both men and women.

For example, in a classical study, Davis and Robinson (1988) grouped the class identities of couples into three ideal types: the first was "independent," i.e., couples' class identities were determined solely by their own social status, independent of one another; the second was "shared," i.e., couples considered both their own and their spouse's socioeconomic status when forming their social class identities; and the third was "dependent," i.e., couples determined their class identities solely by their spouse's socioeconomic status. Davis and Robinson's study found that the class identity of married men in the United States gradually shifted to "independent" in the 1970s and 1980s, while that of married women shifted from "dependent" to "shared." They also argue that the prevalence of feminist attitudes and the increase in women's labor force participation are the main reasons for the shift in the type of couples' class identities. In another study, Wright's point of view is similar to that of Davis and Robinson (Wright and Shin, 1988). As a leading scholar of the neo-Marxist theory of social stratification, Wright continues the Marxist view that one's subjective class identity is primarily influenced by his or her objective class position. In Wright's view, however, one's class positions can be 
either direct or indirect. The direct class position is the direct connection of the person to the means of production, while the indirect class position is the connection to the means of production through others, such as one's spouse. Through a comparative study of the US and Sweden, Wright found that in Sweden, women's direct class position had a more significant effect on their subjective class identity, while in the US, women's class identity was primarily determined by their spouse's class position, which was mainly due to the different economic independence of women in the two countries. Swedish women's labor force participation rates are much higher than American women's, so Swedish women are also more independent in forming their class identity.

In summary, many studies since Goldthorpe's have demonstrated that both the objective social status of the person and the spouse affect an individual's perceptions of one's own class identity, which inspired the theory of "mixed" subjective class identity proposed in this article. Combining those above theoretical and empirical findings of Western countries, I argue that in studying Chinese subjective class identity, the following hypotheses should be made by combining the factors of respondents and their spouses.

Hypothesis 1: Both one's social status and the social status of one's spouse affect an individual's subjective class identity in China.

Another important finding of the literature is that the relative importance of one's own and one's spouse's social status on an individual's subjective class identity varies considerably across gender. The relative importance of one's own and one's spouse's social status may vary across counties with different gender inequalities and females' varying degrees of economic independence. China has a long tradition of patriarchism, and the traditional notions of "male dominance outside (the home) and female dominance within it" and "male superiority over females" have a profound impact on Chinese outlook and values on life. Therefore, I argue that Goldthorpe's traditional view of female class identity may still be valid in China and thus propose the following research hypothesis.

Hypothesis 2: In China, one's own social status has a greater impact on the class identity of men, while the social status of one's spouse has a greater impact on the class identity of women.

\section{The impact of parental status}

The study of the impact of parents' social status or family background on individual status attainment has been an important topic in the research of social stratification and mobility since Blau and Duncan (1967) developed the classical "status attainment model." However, in both Western and Chinese studies, scholars tend to focus only on children's attainment of objective social status, such as education, income, and occupation, and rarely on their subjective status attainment when exploring the impact of family background on children's social status (Ganzeboom et al. 1991). In addition, Western scholars' studies of individual class status have extended the scope of analysis only from the individual to the spouse and rarely further to the parents (Davis and Robinson 1988). This may be because the nuclear family is predominant in Western societies; after reaching adulthood, children mostly leave their parents and live with their spouses, so that they and their spouses form a common living unit, while the ties between parents and adult children are not strong (Chu and Yu 2010). In China, however, the situation is very different. 
First, China has a tradition of extended family and multigenerational co-residence, and many children live with their parents even after marriage (Logan et al. 1998). China's sixth census in 2010 showed that the proportion of stem and joint families with multiple generations was 23.57 percent (Wang 2013), and the proportion of those aged 65 and above living with their children was nearly 50 percent (Wang 2014). In multigenerational families, where children live with their parents, the social status of the parents naturally becomes an important factor in influencing their children's social status and life opportunities. Hence, the social status of the parents is likely to have a direct impact on their children's class identity in China.

Second, many studies on intergenerational relations have found that Chinese parents maintain close contact with their children regardless of whether they co-reside (Bian et al. 1998). These connections can be financial, instrumental, and emotional; they include both the support of children to their parents based on Confucian filial tradition and the various forms of help provided by parents to their adult children (Xu 2017). Complex intergenerational relationships not only bind Chinese children and parents together in daily life but also unify them psychologically. In such cases, children's perceptions and behaviors are likely to be influenced by their parents, making them associate their life situation with their parents' status when evaluating their own class affiliation, either consciously or unconsciously. Therefore, the social status of parents is also an important factor in influencing individual class identity in China.

Finally, many empirical studies on social stratification in China have found that family origin or parental social status significantly impacts many objective socioeconomic status indicators for children, such as education, income, and occupation (Zhang 2004; $\mathrm{Li}$ and Zhu, 2015). Unlike the intergenerational transmission model in Western societies, family background in China not only affects the ultimate status attainment of individuals indirectly through education but also has a significant direct impact on these indicators (Bian 2002). Some longitudinal studies also found that the effect of the family background was stable and showed no signs of weakening, both in terms of the indirect effect via education and the direct effect on final status attainment indicators ( $\mathrm{Li}$, 2007; Li, 2010). Taken together, these studies reveal a strong relationship between parental status and children's class identity in China, a relationship that not only exists de facto but is likely to have been imprinted into Chinese mentality, thus influencing their subjective perceptions of their class identity.

Taken together, I argue that in addition to one's own social status and that of one's spouse, the social status of one's parents is also an important factor influencing Chinese people's class identity and thus propose the following hypothesis:

Hypothesis 3: The social status of the parents has a significant impact on the subjective class identity of the individual.

Although the social status of parents generally affects an individual's class identity, the strength of this influence may show some degree of heterogeneity depending on the individual's age and co-residence status.

First, young people who have just recently become independent from their original families tend to be more financially and emotionally dependent on their parents. Studies of intergenerational relationships also found that parental support for adult children was more pronounced when the children were younger (Xu 2017). Therefore, I argue that the social status of parents has a greater impact on young people's subjective class identity and thus propose the following: 
Hypothesis 4: The social status of parents has a greater impact on the class identity of young people than older people.

Second, living with one's parents means forming a community with them financially and instrumentally, and the sense of being a unit makes individuals more prone to take parental status into account when assessing their class identity. Therefore, we argue that when individuals live with their parents, their class identity is more likely to be influenced by their parental status, which leads to the following research hypothesis:

Hypothesis 5: When individuals live with their parents, their class identity is more influenced by their parents' status than when individuals live independently of their parents.

\section{Class identity bias}

The aforementioned analysis of class identity also provides a new perspective to understand the subjective class identity bias prevalent in China. According to the definition of class identity bias, this bias refers to the extent to which an individual's objective class status is inconsistent with his or her subjective social status (Fan and Chen 2015). In other words, the existence and magnitude of class identify bias are both relative to the objective social status of the individual. However, from the concept of "mixed" subjective class identity, a person's socioeconomic status is not the only criterion for evaluating his or her class identity; the social statuses of his or her spouse and parents can also affect their class identity. Therefore, such deviations are inevitable if the social statuses of the person, the spouse, and the parents differ.

First, many studies on associative mating have found that although Chinese marriages are predominantly homogeneous, it is not uncommon for husbands and wives to have unequal statuses (Li 2011; Qi and Niu 2012). In the case of educational matches in married couples, many studies have indicated that the degree of education homogeneity of married couples in China has gradually increased over time. However, many studies analyzing the data of the past two decades find that the proportion of married Chinese couples in which the education levels of the wife and the husband do not match remains higher than 40 percent. In such heterogamous marriages, the proportion of the husband's education level is higher than that of the wife's in the majority of the cases (Li, 2008b; Xu et al. 2014). If, as noted earlier, the social status of a spouse also affects a person's subjective class identity, then in heterogamous marriages, the higher the status of the spouse is, the more likely the individual is to overestimate his or her own class status, and the lower the status of the spouse is, the more likely the person is to underestimate his or her own class status. In addition, if women's class identity is more likely to be influenced by their spouses' status, we would expect that the effect of spouse's status on class identity bias is also likely to be stronger for females than for males. Taking the above analysis into consideration, I propose the following research hypothesis:

Hypothesis 6: The higher the social status of the spouse is relative to the individual, the more likely the individual's class identity is to be biased upward, while the lower the social status of the spouse is relative to the individual, the more likely the individual's class identity is to be biased downward; the effect of the spouse's relative status on class identity bias is stronger for females than for males. 
Second, the study of intergenerational mobility in contemporary China found that China's overall social mobility rate has increased in the past 60 years. With the continuation of the reform and opening- up and rapid economic transformation, the overall social mobility in China is also accelerating ( $\mathrm{Li}$ and Zhu 2015). It implies that the social statuses of many Chinese people have changed more markedly since the reform and opening -up and that many people's social statuses have improved significantly compared with their parents'. If parents' social status also affects the subjective class identity of Chinese, as mentioned above, it is likely that this inconsistency between parents' and children's social status caused by the social mobility of the offspring is also an important source of class identity bias for the offspring. This bias may be more pronounced in groups that are more affected by parents' social status (e.g., young people and the people living with their parents). As such, I propose the following hypothesis:

Hypothesis 7: The higher the social status of the parents is relative to the respondent's own status, the more likely the individual's class identity is biased upward, while the lower the social status of the parents is relative to the respondent's status, the more likely the individual's class identity is biased downward. The relative status of one's parents is expected to have a greater impact on the class identity bias of young people and people living with their parents.

\section{Social change}

The "mixed" subjective class identity discussed above is, to some extent, based on the Chinese extended family tradition. However, according to the theory of family modernization, in the process of social modernization, the tradition of the extended family gradually declines, eventually being supplanted by the nuclear family as the primary model of the modern family; besides, the relationship between husband and wife will also change from the wife's dependence on her husband to an equal relationship (Tang 2010; Goode 1963).

In recent years, empirical studies of family change have found that the shift from the traditional to the modern family, as predicted by family modernization theory, has been taking place in Chinese society. According to census data, China's average family size decreased from 4.36 in 1982 to 3.10 in 2010. In terms of family structure, the proportion of older people aged 65 and above living with their children has also dropped from nearly 70 percent in 1982 to less than 50 percent in 2010 (Zeng and Wang 2004; Wang 2014; $\mathrm{Xu}$ et al. 2014), with the trend towards smaller families and nuclearization becoming increasingly prominent.

In addition, some localized field studies have also found a tendency of "individualization" of Chinese perceptions and behaviors in the modernization process of society. Yan (2012) pointed out that in the market-oriented reform characterized by "de-collectivization," the concept of the "individual" has been rapidly rising, as noted in a decades-long observation of the northeastern countryside. Not only does this suggest that individuals have greater autonomy and mobility in their economic activities, but it also means that individuals have been liberated from the many constraints imposed on them by their families. Chinese society is experiencing unprecedented individualization. 
If the theoretical predictions of family modernization and Yan's (2012) portrayal of the trend of individualization that has taken place in Chinese society in recent years is correct, it is expected that the Chinese subjective class identity will also become increasingly modernized and individualized. In other words, the subjective class identity of the Chinese population will increasingly be determined by their own class status, and the influence of parents and spouses will gradually diminish. Therefore, I propose the following research hypothesis:

Hypothesis 8: The influence of an individual's class status on subjective class identity gradually increases over time, while the influence of parental and spouse's status gradually decreases over time.

However, we must also note that the theory of family modernization has been questioned and criticized in studies. Opponents of the theory argue that, on the one hand, it is too simplistic to divide families into "traditional families" and "modern families" and that there is a vast middle ground between the two (Shi 2016). On the other hand, the single-line evolutionary assumption that family patterns will change from traditional to modern in all societies is also unrealistic, and a large number of studies have found that the paths of family change in different societies vary significantly depending on the cultural traditions, social structure, and social institutions (Tang 2010; Thornton and Fricke 1987).

Research in China has found that although Chinese families have shown a trend towards downsizing and nucleation during the modernization process, multigenerational families remain an important type of family (Wang 2004), and even though more children choose to live apart from their parents after marriage, they do not entirely break the ties with parents. In fact, because of the high living cost and the prevalence of female employment, young adults have become more dependent on their parents in terms of finances, housing, and childcare (Xu 2013). Studies on intergenerational mobility have also found that the impact of parents' status on children's education, income, and occupational status shows no sign of weakening as society modernizes ( $\mathrm{Li}$ 2007).

Moreover, gender equality predicted by modernization theory has not been fully realized in China either. Although the educational status of women has gradually caught up with or even surpassed that of men (Ye and Wu 2011), this has not eliminated the considerable gap between men and women in terms of income and occupational status (He and Wu 2015). Within the family, women still carry out more household chores than men. The traditional gender division of labor, which, as mentioned earlier, is "male dominance outside the home and female dominance within it" has not changed substantially either (Yu 2014; Tong and Liu 2015). Moreover, in terms of gender attitudes, there has been a clear trend towards a return to tradition after 2000 for both men and women, urban and rural, young and old (Xu 2016; Yang et al. 2014).

Taken together, I argue that the gradual diminishing of the family, as assumed by modernization and individualization theories, does not necessarily hold in China. Therefore, the influence of parents and spouse's social statuses on individual class identity does not necessarily decrease over time. Accordingly, I propose a hypothesis that is opposite to hypothesis 8 :

Hypothesis 9: The effect of individual class status on subjective class identity decreases, while the effect of parents and spousal status increases over time. 
I will test whether the survey data support hypothesis 8 or hypothesis 9 .

\section{Data and variables}

This article uses data from the Chinese General Social Survey (CGSS) in 2010 and 2013 (CGSS 2010 and CGSS 2013, respectively). The Chinese General Social Survey is a large-scale comprehensive social survey designed and implemented by the China Survey and Data Center of the Renmin University of China. The survey treats the district/ county as the primary sampling unit, the village/neighborhood committee as the secondary sampling unit, and the household as the tertiary sampling unit. Within each sampled household, an adult between the age of 18 and 70 is selected to take the survey, whose information is collected, such as family, marriage, employment and income, and attitudes and behavior.

CGSS 2010 and CGSS 2013 surveyed 11,783 and 11,438 Chinese citizens, respectively, but due to missing data, the actual sample sizes used for the analysis were 10,004 and 9923, respectively. So, the total size is 19,927 . The missing information is mainly from the measurements of the social statuses of the respondents, their spouses, and parents. To assess the influence of the missing values, I use the multiple imputation method to impute the missing values and finds little difference in the results regardless of whether the missing values are imputed. Considering the space limitation, I only report the results based on casewise deletions.

In both the 2013 and 2010 surveys, CGSS used a 10-level scale to measure respondents' class identity, with 1 indicating the bottom and 10 indicating the top. Higher scores indicate a higher assessment of a respondent's class status.

The key independent variables in this paper are the social status of the respondents themselves and those of their parents and spouses. Considering that social status is a complex concept with multiple dimensions, I measure multiple aspects of it.

Specifically, the respondent's objective social status and their spouse's status are measured in three dimensions: income, years of education, and party membership. Education and income are two indicators commonly used in existing studies to measure social status. Another commonly used indicator is the socioeconomic index of occupation (ISEI). However, considering many missing values in the occupational status of the respondents and their spouses in CGSS 2010 and CGSS 2013, which would lead to a reduced sample size, we switched to another indicator: party membership. Party membership is a widely used social status measure in the Chinese context. In China, being a member of the Communist Party of China is not only an important condition for entry into certain professions (such as civil servants) and promotion, but the party recruitment process also takes into account the candidate's social status (Walder et al. 2000). Thus, party membership can also reflect the social statuses of respondents and their spouses to some extent.

Regarding the social status of parents, three indicators are used: the highest years of schooling of the parents at the respondent's age of 14, the highest occupational ISEI score of the parents at the respondent's age of 14, and the subjective evaluation of the social status of the family at the respondent's age of 14. Parental education and professional status are the two most common indicators used to measure parental status in existing studies. Because the respondent's family status at age 14 was determined mainly by his or her parents' status, I classify it into the measurement of parents' status. 
Finally, given the strong correlation among the various social status measures, it is difficult to incorporate all of them into the model to obtain valuable results. Therefore, I first condensed these factors into a composite social status index using factor analysis before modeling. The results of the factor analysis are shown in Table 1. The three-factor scores of the social statuses of the respondents, their parents, and their spouses all have mean zero with standard deviations of $0.6,0.8$, and 0.7 , respectively. The maximum value of social status of the respondents is 1.91 , and the minimum value is -1.32 ; the maximum value of social status of parents is 3.11 , and the minimum value is -1.05 ; the maximum value of social status of the spouse is 2.00 , and the minimum value is -1.48 .

Based on the objective social status index obtained from the factor analysis and the subjective evaluation of the respondent's own social class, we can obtain a measure of the bias of the respondent's subjective class identity. Specifically, I first divide the respondents' objective socioeconomic status index into deciles, which gives us an ordinal measure of the objective social status with ten categories. We then subtract this ordinal measure by the subjective class identity of the respondent to obtain the deviation between that respondent's subject and objective class status. If this deviation is zero, it means that the subjective class is not biased; if it is negative, it means that the subjective class identity has downward bias; if it is positive, it means that the subjective class has an upward bias.

In addition to the key variables mentioned above, I controlled for respondents' gender, age, marital status, place of residence, and co-residence status with their parents in the models. Furthermore, considering that status process theory and reference group theory are important in existing research to explain Chinese subjective class identity and its biases, we also controlled for two variables in our analysis. They are respondents' perceptions of class mobility in comparison to their social statuses 10 years ago and their social statuses relative to their same-cohort peers. Moreover, we also control for respondents' ownership of housing and cars to take into account the important influences of housing and cars on an individual's subjective class identity.

Table 2 shows descriptive statistics for all the variables. First, in terms of dependent variables, the average score of class identity in 2013 was 4.3 out of 10, which shows an increase of 0.3 points compared with 2010. In terms of class identity bias, both the 2010 and 2013 values were negative, indicating that Chinese people tend to

Table 1 Results of the factor analysis

\begin{tabular}{|c|c|c|c|c|c|}
\hline \multicolumn{2}{|c|}{ Personal social status } & \multicolumn{2}{|l|}{ Parental social status } & \multicolumn{2}{|c|}{ Spousal social status } \\
\hline Indicator & $\begin{array}{l}\text { Factor } \\
\text { loading }\end{array}$ & Indicator & $\begin{array}{l}\text { Factor } \\
\text { loading }\end{array}$ & Indicator & $\begin{array}{l}\text { Factor } \\
\text { loading }\end{array}$ \\
\hline $\begin{array}{l}\text { Years of } \\
\text { education }\end{array}$ & 0.392 & Family social status at age 14 & 0.454 & $\begin{array}{l}\text { Years of } \\
\text { education }\end{array}$ & 0.447 \\
\hline $\begin{array}{l}\text { Logarithmic } \\
\text { income }\end{array}$ & 0.474 & $\begin{array}{l}\text { Highest year of parents' education } \\
\text { at age } 14\end{array}$ & 0.652 & $\begin{array}{l}\text { Logarithmic } \\
\text { income }\end{array}$ & 0.543 \\
\hline $\begin{array}{l}\text { Party } \\
\text { membership }\end{array}$ & 0.401 & Highest ISEI occupation at age 14 & 0.628 & $\begin{array}{l}\text { Party } \\
\text { membership }\end{array}$ & 0.408 \\
\hline alpha $=0.317$ & & alpha $=0.412$ & & alpha $=0.414 a$ & \\
\hline
\end{tabular}

Note: The alpha coefficient does not exceed 0.5 for two possible reasons: first, all of the factor analyses include only three indicators, and the alpha coefficient tends to be lower when there are fewer indicators; second, there may be inconsistencies in the social status of individuals across indicator dimensions, such as the fact that those with a higher education do not necessarily have higher incomes. However, in any case, because of the strong correlation between the indicators, if all the indicators are included in the model, the statistical results of some of the indicators will not be significant because of the problem of multicollinearity, especially when the test involves interaction terms, so extracting the common factor through factor analysis is the only feasible way 
underestimate their class status in general. If the deviation is taken in absolute values, the mean is 2.7 in both surveys. In other words, there is an average difference of almost three levels between their subjective and objective class status. Therefore, in general, bias is prevalent.

Second, regarding the independent variables, except for the increase in the individual and spouse's income in 2013, which are the other measures of the social status of the person, his or her spouse and parents' measurements were not significantly different in the two waves of the survey. In terms of control variables, the proportions of men and women in the sample were roughly equal; the average age was approximately 48 years; approximately 80 percent were married, and approximately 10 percent each were unmarried and widowed or divorced; 60 percent lived in urban areas, and 40 percent lived in rural areas; approximately 13 percent lived with their parents. Compared with their peers, 61.3 percent of the respondents evaluated their social status roughly the same, while the proportion of those who considered themselves to be of lower status (31 percent) was significantly higher than the proportion who considered themselves to be of higher status ( 4.5 percent). Compared with 10 years ago, nearly one-third of the respondents believed that their social statuses had not changed; approximately 55 percent believed that their statuses had improved; only approximately 13 percent believed that their statuses had decreased. Compared with the 2010 survey, there was a significant increase in the proportion of people who considered their statuses to be higher than 10 years ago in the 2013 survey. Finally, housing and car ownership also increased significantly in 2013 compared with 2010. Overall, most socioeconomic indicators in 2010 and 2013 remained consistent, but income and house and car ownership were all higher in 2013 than in 2010, which may be an important factor underlying why more respondents felt their statuses had improved in 2013.

Finally, note that since the respondent's social status compared with their peers' was not surveyed in 2010, and since the 2013 data are more recent, in the model analysis below, we will mainly use the 2013 data while including both years in the sample only for comparative studies involving social changes.

\section{Results}

\section{The effect of parents' social status}

The four models in Table 3 focus on the effects of the respondent's own and parents' objective social statuses on the respondent's subjective class identity. Of these, model 1 is the baseline model that incorporates one's own objective social status and all other control variables. The results of the analysis show that the higher one's objective social status is, the higher one's subjective class identity is, which verifies the classic "status determinism" theory. In addition to one's objective social status, there are several factors that also have a significant impact on an individual's class identity. Specifically, men's subjective class identity is lower than that of women, urban residents' subjective class identity is higher than that of rural people, and the subjective class identity of the married is higher than that of the unmarried. In terms of family property, owning multiple homes significantly increases an individual's subjective class identity, and having a car also has a significant positive impact on class identity, which illustrates the important role that house and car ownership plays in differentiating social classes in Chinese 
Table 2 Descriptive statistics for each variable

\begin{tabular}{|c|c|c|c|c|}
\hline Variables & Categories/statistics & 2010 & 2013 & Total \\
\hline \multicolumn{5}{|l|}{ Dependent variable } \\
\hline \multirow[t]{2}{*}{ Subjective class identity (point) } & Mean & 4.0 & 4.3 & 4.2 \\
\hline & S. D. & 1.7 & 1.7 & 1.7 \\
\hline \multirow[t]{2}{*}{ Class identity bias (point) } & Mean & -1.4 & -1.3 & -1.3 \\
\hline & S. D. & 3.0 & 3.0 & 3.0 \\
\hline \multirow{2}{*}{$\begin{array}{l}\text { Absolute value of class } \\
\text { identity bias (point) }\end{array}$} & Mean & 2.7 & 2.7 & 2.7 \\
\hline & S. D. & 2.0 & 1.8 & 1.9 \\
\hline \multicolumn{5}{|l|}{ Independent variable } \\
\hline \multicolumn{5}{|l|}{ Individual's social economic status (SES) } \\
\hline \multirow[t]{2}{*}{ Years of schooling (year) } & Mean & 8.6 & 8.7 & 8.7 \\
\hline & S. D. & 4.5 & 4.6 & 4.6 \\
\hline \multirow[t]{2}{*}{ Income (yuan) } & Mean & $\begin{array}{l}18, \\
039.0\end{array}$ & $\begin{array}{l}22, \\
621.6\end{array}$ & $\begin{array}{l}20, \\
321.0\end{array}$ \\
\hline & S. D. & $\begin{array}{l}80 \\
211.4\end{array}$ & $\begin{array}{l}36 \\
337.9\end{array}$ & $\begin{array}{l}62, \\
390.7\end{array}$ \\
\hline \multirow[t]{2}{*}{ Party membership (\%) } & No & 87.4 & 89.9 & 88.6 \\
\hline & Yes & 12.6 & 10.1 & 11.4 \\
\hline \multirow[t]{2}{*}{ Individual's SES score (point) } & Mean & 0.0 & 0.0 & 0.0 \\
\hline & S. D. & 0.6 & 0.6 & 0.6 \\
\hline \multicolumn{5}{|l|}{ Parents' SES } \\
\hline \multirow{2}{*}{$\begin{array}{l}\text { Family social class score } \\
\text { at respondent's age } 14 \text { (point) }\end{array}$} & Mean & 2.9 & 3.1 & 3.0 \\
\hline & S. D. & 1.9 & 1.8 & 1.8 \\
\hline \multirow{2}{*}{$\begin{array}{l}\text { Parents' highest year of schooling at respondent's age } 14 \\
\text { (year) }\end{array}$} & Mean & 4.9 & 5.0 & 5.0 \\
\hline & S. D. & 4.6 & 4.6 & 4.6 \\
\hline \multirow{2}{*}{$\begin{array}{l}\text { Parents' highest occupation ISEI } \\
\text { at respondent's age } 14 \text { (point) }\end{array}$} & Mean & 32.1 & 31.3 & 31.7 \\
\hline & S. D. & 14.9 & 14.6 & 14.7 \\
\hline \multirow[t]{2}{*}{ Parents' SES score (point) } & Mean & 0.0 & 0.0 & 0.0 \\
\hline & S. D. & 0.8 & 0.8 & 0.8 \\
\hline \multicolumn{5}{|l|}{ Spouse's SES } \\
\hline \multirow[t]{2}{*}{ Years of schooling (year) } & Mean & 8.5 & 8.5 & 8.5 \\
\hline & S. D. & 4.3 & 4.4 & 4.3 \\
\hline \multirow[t]{2}{*}{ Income (yuan) } & Mean & $\begin{array}{l}16 \\
621.6\end{array}$ & $\begin{array}{l}22, \\
089.8\end{array}$ & $\begin{array}{l}19, \\
400.9\end{array}$ \\
\hline & S. D. & $\begin{array}{l}34, \\
391.5\end{array}$ & $\begin{array}{l}31 \\
063.6\end{array}$ & $\begin{array}{l}32, \\
855.2\end{array}$ \\
\hline \multirow[t]{2}{*}{ Party membership (\%) } & No & 89.8 & 91.9 & 90.8 \\
\hline & Yes & 10.2 & 8.1 & 9.2 \\
\hline \multirow[t]{2}{*}{ Spouse's SES score (point) } & Mean & 0.0 & 0.0 & 0.0 \\
\hline & S. D. & 0.7 & 0.7 & 0.7 \\
\hline \multicolumn{5}{|l|}{ Control variable } \\
\hline \multirow[t]{2}{*}{ Gender (\%) } & Female & 51.4 & 49.5 & 50.4 \\
\hline & Male & 48.6 & 50.6 & 49.6 \\
\hline \multirow[t]{2}{*}{ Age (year) } & Mean & 47.4 & 48.8 & 48.1 \\
\hline & S. D. & 15.2 & 16.2 & 15.7 \\
\hline \multirow[t]{2}{*}{ Marital status (\%) } & Unmarried & 8.3 & 10.0 & 9.1 \\
\hline & Married & 81.8 & 79.6 & 80.7 \\
\hline
\end{tabular}


Table 2 Descriptive statistics for each variable (Continued)

\begin{tabular}{lllll}
\hline Variables & Categories/statistics & 2010 & 2013 & Total \\
\hline & Divorced or & 9.9 & 10.4 & 10.2 \\
Place of residence (\%) & Widowed & & & \\
& Rural & 40.4 & 40.4 & 40.4 \\
Whether co-reside with parents (\%) & Urban & 59.6 & 59.6 & 59.6 \\
& No & 87.4 & 86.1 & 86.8 \\
Class status compared with peers (\%) & Yes & 12.6 & 13.9 & 13.2 \\
& Higher & & 4.5 & 4.5 \\
& Similar & & 61.3 & 61.3 \\
Perceptions of social mobility (\%) & Lower & & 34.1 & 34.1 \\
& Downward & 14.7 & 11.7 & 13.2 \\
House ownership (\%) & Immobile & 32.8 & 29.8 & 31.3 \\
& Upward & 52.5 & 58.5 & 55.5 \\
& No house & 7.3 & 6.0 & 6.7 \\
Sample size (person) & Have one house & 78.4 & 80.7 & 79.5 \\
& Have multiple & 14.3 & 13.4 & 13.8
\end{tabular}

Note: Spouses' years of education, income, party membership, and composite SES scores are only counted for the sample with spouses

society today. Finally, the reference group theory and status process theory, which have been particularly emphasized by previous scholars, are also supported by model 1 . The results of the analysis show that the lower the perceived social status of the individuals compared with their peers is, the lower their subjective class identity is, and individuals with a significant sense of upward social mobility tend to have a higher class identity. These findings revalidate the findings of previous scholars and provide the basis for the analysis in this study.

Model 2 incorporates the social status of the respondent's parents into model 1. After controlling for other variables, the social status of parents has a large positive effect on the subjective class identity of individuals, which indicates that in addition to their own social status, the social status of parents is also an important reference for an individual to assess his or her class identity. Moreover, the standardized regression coefficient of parents' social status is 0.233 , while the standardized regression coefficient of an individual's own social status is 0.074 , so the relative influence of parents' social status on individual class identity is relatively stronger. Thus, hypothesis 3 is supported.

In addition, to further test the differential effects of parents' social status on different groups, the interaction terms of parents' social status and respondent age and living arrangements with parents are added to model 2. From models 3 and 4, it is found that the interaction term between parents' social status and the age group over 35 years is significantly negative, while the interaction term with parental co-residence ss significantly positive, suggesting that parents' social status has a greater impact on the subjective class identity of the younger people and people who live with their parents. As mentioned earlier, this may be because people who are younger and live with their parents are more financially and emotionally dependent on them, and so they are more 
Table 3 The effect of parents' social status on children's subjective class identity $(N=9923)$

\begin{tabular}{|c|c|c|c|c|}
\hline & Model 1 & Model 2 & Model 3 & Model 4 \\
\hline \multirow[t]{2}{*}{ Male } & $-0.217^{* * *}$ & $-0.162^{* * *}$ & $-0.163^{* * *}$ & $-0.149^{* * *}$ \\
\hline & $(0.031)$ & $(0.031)$ & $(0.031)$ & $(0.031)$ \\
\hline \multirow[t]{2}{*}{ Age } & 0.001 & $0.008^{* * *}$ & $0.009^{* * *}$ & $0.007^{* * *}$ \\
\hline & $(0.001)$ & $(0.001)$ & $(0.001)$ & $(0.001)$ \\
\hline \multirow[t]{2}{*}{ Urban residency } & $0.202^{* * *}$ & $0.073^{*}$ & $0.072^{*}$ & $0.066^{*}$ \\
\hline & $(0.033)$ & $(0.033)$ & $(0.033)$ & $(0.033)$ \\
\hline \multicolumn{5}{|l|}{ Marital status (unmarried $=0$ ) } \\
\hline \multirow[t]{2}{*}{ Married } & $0.127^{*}$ & $0.250^{* * *}$ & $0.311^{* * *}$ & $0.254^{* * *}$ \\
\hline & $(0.054)$ & $(0.054)$ & $(0.057)$ & $(0.057)$ \\
\hline \multirow[t]{2}{*}{ Divorced or widowed } & 0.047 & 0.135 & $0.187^{*}$ & 0.149 \\
\hline & $(0.076)$ & $(0.075)$ & $(0.076)$ & $(0.076)$ \\
\hline \multicolumn{5}{|l|}{ Number of houses (no house $=0$ ) } \\
\hline \multirow[t]{2}{*}{ Own one house } & 0.107 & 0.074 & 0.075 & 0.079 \\
\hline & $(0.063)$ & $(0.062)$ & $(0.062)$ & $(0.062)$ \\
\hline \multirow[t]{2}{*}{ Own multiple houses } & $0.309^{* * *}$ & $0.230^{* *}$ & $0.228^{* *}$ & $0.233^{* *}$ \\
\hline & $(0.074)$ & $(0.073)$ & $(0.073)$ & $(0.073)$ \\
\hline \multirow[t]{2}{*}{ Have a car } & $0.427^{* * *}$ & $0.344^{* * *}$ & $0.335^{* * *}$ & $0.340^{* * *}$ \\
\hline & $(0.043)$ & $(0.042)$ & $(0.042)$ & $(0.042)$ \\
\hline \multicolumn{5}{|l|}{ Relative social status to peers (higher $=0$ ) } \\
\hline \multirow[t]{2}{*}{ Similar } & $-0.803^{* * *}$ & $-0.787^{* * *}$ & $-0.784^{* * *}$ & $-0.786^{* * *}$ \\
\hline & $(0.073)$ & $(0.071)$ & $(0.071)$ & $(0.071)$ \\
\hline \multirow[t]{2}{*}{ Lower } & $-1.722^{* * *}$ & $-1.655^{* * *}$ & $-1.649^{* * *}$ & $-1.654^{* * *}$ \\
\hline & $(0.076)$ & $(0.074)$ & $(0.074)$ & $(0.074)$ \\
\hline \multicolumn{5}{|l|}{ Perception of social mobility (downward $=0$ ) } \\
\hline \multirow[t]{2}{*}{ Immobile } & $0.224^{* * *}$ & $0.279^{* * *}$ & $0.280^{* * *}$ & $0.278^{* * *}$ \\
\hline & $(0.051)$ & $(0.050)$ & $(0.050)$ & $(0.050)$ \\
\hline \multirow[t]{2}{*}{ Upward } & $1.059^{* * *}$ & $1.179^{* * *}$ & $1.179^{* * *}$ & $1.179^{* * *}$ \\
\hline & $(0.047)$ & $(0.047)$ & $(0.047)$ & $(0.047)$ \\
\hline \multirow[t]{2}{*}{ Individual's social status } & $0.373^{* * *}$ & $0.206^{* * *}$ & $0.213^{* * *}$ & $0.211^{* * *}$ \\
\hline & $(0.030)$ & $(0.030)$ & $(0.030)$ & $(0.030)$ \\
\hline \multirow[t]{2}{*}{ Parents' social status } & & $0.502^{* * *}$ & $0.766^{* * *}$ & $0.481^{* * *}$ \\
\hline & & $(0.024)$ & $(0.092)$ & $(0.025)$ \\
\hline \multirow[t]{2}{*}{ Above 35 years old } & & & -0.037 & \\
\hline & & & $(0.054)$ & \\
\hline \multirow[t]{2}{*}{ Parents' social status $\times$ above 35 years old } & & & $-0.150^{* *}$ & \\
\hline & & & $(0.050)$ & \\
\hline \multirow[t]{2}{*}{ Co-reside with parents } & & & & $-0.132^{*}$ \\
\hline & & & & $(0.052)$ \\
\hline \multirow[t]{2}{*}{ Parent social status $\times$ co-reside with parents } & & & & $0.161^{* *}$ \\
\hline & & & & $(0.058)$ \\
\hline \multirow[t]{2}{*}{ Intercept } & $4.339^{* * *}$ & $3.890^{* * *}$ & $3.839 * * *$ & $3.928^{* * *}$ \\
\hline & $(0.121)$ & $(0.121)$ & $(0.128)$ & $(0.124)$ \\
\hline$R^{2}$ & 0.243 & 0.275 & 0.276 & 0.276 \\
\hline $\begin{array}{l}{ }^{+} p<0.10 \\
{ }^{*} p<0.05 \\
{ }^{* *} p<0.01 \\
{ }^{* * *} p<0.001\end{array}$ & & & & \\
\hline
\end{tabular}


likely to take their parents into account when assessing their class identity. Based on the results of model 3 and model 4, hypothesis 4 and hypothesis 5 are also supported.

The analysis of Table 3 shows that, in addition to one's own social status, the social status of one's parents is also an important factor that affects the individual's class identity. Therefore, is the social status of one's parents an important source of class identity bias? To answer this question, we replaced the dependent variable in Table 3 with class identity bias and repeated the analysis.

In Table 4, model 5 is the baseline model, from which it is found that male, younger and urban-dwelling individuals are more likely to underestimate their class status, and individuals who own at least one house (and especially multiple houses) and have a car are more likely to overestimate their class status. In addition, the lower an individual's social class status is relative to his or her peers, the more likely his or her subjective class identity is to be downwardly biased, while those perceiving upward mobility are more likely to have an upward biased class identity, confirming the influence of reference group theory and status process theory on class identity bias. Finally, after controlling for the factors mentioned above, the higher the objective social status of an individual is, the more likely his or her subjective class identity will be shifted downward, which, on the one hand, is due to the "ceiling effect" of class identity bias, i.e., people at the top of society cannot be shifted upward but only downward, while people at the bottom of society cannot be shifted downward but only upward (Fan and Chen 2015). On the other hand, this also reflects the tendency of Chinese people to have a "middle-class identity" or a lower-class identity to some extent (Fan and Chen 2015).

Model 6 incorporates parents' social status based on model 5, and the results show that parents' social status has a significant positive effect on individual class identity bias after controlling for other factors. This suggests that individuals tend to overestimate their class status when their parents' social status is high and that individuals tend to underestimate their class status when their parents' social status is low; thus, parents' social status is indeed an important factor in influencing individual class identity bias.

In addition, from models 7 and 8 , it is found that the effect of parental social status on class identity bias can show significant heterogeneity depending on the age of the individual and the living arrangement with the parents. Specifically, the effect of parents' social status is weaker for older individuals and those who do not live with their parents, while the effect of parents' social status is stronger for younger individuals and those who live with their parents. These findings reaffirm the findings in Table 3. Based on the results of models 6 to 8 , hypothesis 7 is supported.

\section{The effect of the spousal status}

We build on the analysis of the impact of parents' social status on individual subjective class identity and its bias to further analyze the effect of the spouse's social status. For this purpose, we confined the sample to those married and got a reduced sample size in Table 5.

First, the study of subjective class identity shows that the social statuses of the respondents themselves, their parents, and their spouses all have a significant positive effect on class identity when including all control variables, and so hypothesis 1 is supported. The standardized regression coefficient for an individual's social status is 
Table 4 The effect of parents' social status on children's class identify bias ( $N=9923)$

\begin{tabular}{lllll}
\hline & Model 5 & Model 6 & Model 7 & Model 8 \\
\hline Male & $-0.370^{* * *}$ & $-0.325^{* * *}$ & $-0.326^{* * *}$ & $-0.306^{* * *}$ \\
& $(0.036)$ & $(0.035)$ & $(0.035)$ & $(0.036)$ \\
Age & $0.010^{* * *}$ & $0.015^{* * *}$ & $0.014^{* * *}$ & $0.014^{* * *}$ \\
& $(0.001)$ & $(0.001)$ & $(0.002)$ & $(0.001)$ \\
Urban residency & $-0.180^{* * *}$ & $-0.285^{* * *}$ & $-0.286^{* * *}$ & $-0.297^{* *}$ \\
& $(0.038)$ & $(0.038)$ & $(0.038)$ & $(0.038)$
\end{tabular}

Marital status (unmarried $=0$ )

Married

Divorced or widowed

House ownership (no house $=0$ )

One house

Multiple houses

Have a car

Relative social status to peers (higher $=0$ )

Similar

Lower

Perception of social mobility (downward $=0$ )

Immobile

Upward

Individual's social status

Parents' social status

Above 35 years old

Parents' social status $\times$ above 35 years old

Co-reside with parents

Parents' social status $\times$ co-reside with parents

Intercept

$\mathrm{R}^{2}$

${ }^{+} p<0.10$

${ }^{*} p<0.05$

${ }^{* *} p<0.01$

$p<0.001$

$\begin{array}{llll}0.090 & 0.190^{* *} & 0.250^{* * *} & 0.210^{* *} \\ (0.063) & (0.062) & (0.066) & (0.067) \\ -0.024 & 0.048 & 0.108 & 0.083 \\ (0.087) & (0.087) & (0.088) & (0.089)\end{array}$

$\begin{array}{llll}0.163^{*} & 0.135 & 0.127 & 0.140 \\ (0.073) & (0.072) & (0.072) & (0.072) \\ 0.367^{* * *} & 0.303^{* * *} & 0.289^{* * *} & 0.303^{* * *} \\ (0.085) & (0.084) & (0.084) & (0.084) \\ 0.423^{* * *} & 0.355^{* * *} & 0.343^{* * *} & 0.347^{* * *} \\ (0.049) & (0.049) & (0.049) & (0.049)\end{array}$

$\begin{array}{llll}-0.777^{* * *} & -0.763^{* * *} & -0.765^{* * *} & -0.762^{* * *} \\ (0.083) & (0.082) & (0.082) & (0.082) \\ -1.593^{* * *} & -1.539^{* * *} & -1.539^{* * *} & -1.535^{* * *} \\ (0.087) & (0.086) & (0.086) & (0.086)\end{array}$

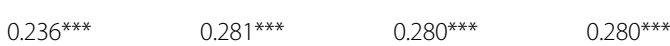

$\begin{array}{llll}(0.058) & (0.058) & (0.058)\end{array}$

$1.073^{* * *} \quad 1.172^{* * *} \quad 1.171^{* * *} \quad 1.171^{* * *}$

(0.055) (0.054) (0.054) (0.054)

$-3.968^{* * *}-4.104^{* * *}-4.097^{* * *}-4.094^{* * *}$

(0.034) (0.035) (0.035) (0.035)

$0.410^{* * *} \quad 0.848^{* * *} \quad 0.371^{* * *}$

$\begin{array}{lll}(0.028) & (0.107) \quad(0.030)\end{array}$

0.086

$(0.062)$

$-0.248^{* * *}$

(0.058)

$-0.202^{* * *}$

(0.060)

$0.288^{* * *}$

$(0.067)$

$-1.323^{* * *}-1.689^{* * *} \quad-1.857^{* * *} \quad-1.642^{* * *}$

$\begin{array}{llll}(0.139) & (0.140) & (0.149)\end{array}$

$\begin{array}{llll}0.687 & 0.694 & 0.694 & 0.695\end{array}$


Table 5 The effect of spouse's social status on individual class identity and bias ( $N=7645)$

\begin{tabular}{|c|c|c|c|c|}
\hline & \multicolumn{2}{|c|}{ Subjective class identity } & \multicolumn{2}{|c|}{ Class identity bias } \\
\hline & Model 9 & Model 10 & Model 11 & Model 12 \\
\hline \multirow[t]{2}{*}{ Male } & -0.027 & -0.027 & $-0.252^{* * *}$ & $-0.265^{* * *}$ \\
\hline & $(0.039)$ & $(0.039)$ & $(0.045)$ & $(0.045)$ \\
\hline \multirow[t]{2}{*}{ Age } & $0.009^{* * *}$ & $0.009^{* * *}$ & $0.017^{* * *}$ & $0.017^{* * *}$ \\
\hline & $(0.001)$ & $(0.001)$ & $(0.001)$ & $(0.001)$ \\
\hline \multirow[t]{2}{*}{ Urban residency } & 0.025 & 0.024 & $-0.356^{* * *}$ & $-0.359^{* * *}$ \\
\hline & $(0.038)$ & $(0.038)$ & $(0.044)$ & $(0.044)$ \\
\hline \multicolumn{5}{|c|}{ House ownership (no house $=0$ ) } \\
\hline \multirow[t]{2}{*}{ One house } & 0.098 & 0.104 & 0.142 & 0.143 \\
\hline & $(0.077)$ & $(0.077)$ & $(0.088)$ & $(0.088)$ \\
\hline \multirow[t]{2}{*}{ Multiple houses } & $0.270^{* *}$ & $0.268^{* *}$ & $0.310^{* *}$ & $0.300^{* *}$ \\
\hline & $(0.088)$ & $(0.087)$ & $(0.101)$ & $(0.101)$ \\
\hline \multirow[t]{2}{*}{ Have a car } & $0.348^{* * *}$ & $0.345^{* * *}$ & $0.344^{* * *}$ & $0.338^{* * *}$ \\
\hline & $(0.047)$ & $(0.047)$ & $(0.054)$ & $(0.054)$ \\
\hline \multicolumn{5}{|c|}{ Relative social status to peers (higher $=0$ ) } \\
\hline \multirow[t]{2}{*}{ Similar } & $-0.830^{* * *}$ & $-0.816^{* * *}$ & $-0.842^{* * *}$ & $-0.805^{* * *}$ \\
\hline & $(0.081)$ & $(0.081)$ & $(0.093)$ & $(0.093)$ \\
\hline \multirow[t]{2}{*}{ Lower } & $-1.669^{* * *}$ & $-1.646^{* * *}$ & $-1.578^{* * *}$ & $-1.530^{* * *}$ \\
\hline & $(0.085)$ & $(0.085)$ & $(0.098)$ & $(0.098)$ \\
\hline
\end{tabular}

Perception of social mobility (downward $=0$ )

\begin{tabular}{|c|c|c|c|c|}
\hline \multirow[t]{2}{*}{ Immobile } & $0.268^{* * *}$ & $0.268^{* * *}$ & $0.291^{* * *}$ & $0.293^{* * *}$ \\
\hline & $(0.058)$ & $(0.058)$ & $(0.067)$ & $(0.067)$ \\
\hline \multirow[t]{2}{*}{ Upward } & $1.154^{* * *}$ & $1.153^{* * *}$ & $1.171^{* * *}$ & $1.170^{* * *}$ \\
\hline & $(0.055)$ & $(0.055)$ & $(0.063)$ & $(0.063)$ \\
\hline \multirow[t]{2}{*}{ Individual's social status } & $0.131^{* * *}$ & 0.007 & $-4.133^{* * *}$ & $-4.415^{* * *}$ \\
\hline & $(0.037)$ & $(0.051)$ & $(0.042)$ & $(0.058)$ \\
\hline \multirow[t]{2}{*}{ Parents' social status } & $0.439^{* * *}$ & $0.443^{* * *}$ & $0.330^{* * *}$ & $0.343^{* * *}$ \\
\hline & $(0.027)$ & $(0.027)$ & $(0.032)$ & $(0.032)$ \\
\hline \multirow{2}{*}{ Spouse's social status } & $0.192^{* * *}$ & $0.340^{* * *}$ & $0.167^{* * *}$ & $0.310^{* * *}$ \\
\hline & $(0.034)$ & $(0.049)$ & $(0.039)$ & $(0.056)$ \\
\hline \multirow[t]{2}{*}{ Individual's social status $\times$ male } & & $0.236^{* * *}$ & & $0.556^{* * *}$ \\
\hline & & $(0.069)$ & & $(0.079)$ \\
\hline \multirow[t]{2}{*}{ Spouse's social status $\times$ male } & & $-0.268^{* * *}$ & & $-0.273^{* * *}$ \\
\hline & & $(0.063)$ & & $(0.072)$ \\
\hline \multirow[t]{2}{*}{ Intercept } & $4.066^{* * *}$ & $4.017^{* * *}$ & $-1.535^{* * *}$ & $-1.617^{* * *}$ \\
\hline & $(0.139)$ & $(0.139)$ & $(0.160)$ & $(0.160)$ \\
\hline$R^{2}$ & 0.266 & 0.268 & 0.690 & 0.692 \\
\hline
\end{tabular}

0.046; the standardized regression coefficient for parents' social status is 0.191; the standardized regression coefficient for the spouse's social status is 0.075 . Therefore, the relative impact of the social statuses of parents and spouses on individual class identity is greater than an individual's own objective social status. Although the differences in 
measuring the social statuses of the respondents, their parents, and spouses reduce the comparability of the standardized regression coefficients to a certain extent, the results at least show that the social statuses of the respondents themselves, their parents, and their spouses affect the subjective class identity to varying degrees, so the concept of "mixed" class identity proposed here is supported by the data.

Based on model 9, model 10 incorporates the interaction terms between the respondent's social status, the spouse's social status of the spouse, and the respondent's gender. With the addition of the two interaction terms, the regression coefficient of an individual's social status decreases considerably compared with model 9 and becomes statistically insignificant, while that of the spouse's social status increases significantly. Since the two regression coefficients actually reflect the effect of one's social status and that of one's spouse on the class identity of women after adding the interaction term, this result suggests that for married women, the effect of one's own social status on class identity is not significant but that it is the social status of one's husband that has the real effect. In addition, the interaction term also shows that the social status of oneself has a greater impact on the class identity of men, while the spouse's social status has a greater impact on the class identity of women. Therefore, Goldthorpe's suggestion of women's dependence on husbands' social status is still valid in China, and hypothesis 2 is supported by the data.

Second, the results of the study of class identity bias are mostly as same as before. Model 11 shows that the higher the social status of the spouse is, the more an individual tends to overestimate his or her class status after controlling for all the variables, while the lower the social status of the spouse is, the more an individual tends to underestimate his or her class status, which confirms the significant effect of spouse's social status on class identity bias. In addition, the model shows that one's own social status has a greater impact on the class identity bias of men and that the spouse's social status has a greater impact on the class identity bias of women. Therefore, hypothesis 6 is also supported by the data.

\section{Social change}

Having investigated how the social statuses of the individual, the individual's spouse, and parents affect individual class identity and its bias, I now turn to examine whether the effect of these three variables changes over time. To answer this question, I compare the differences in the effects of these three variables across survey years by adding the results of the 2010 CGSS data.

From Table 6, it can be seen that after controlling for other variables, both the social statuses of the individual and parents had a significant positive effect on class identity, both in the 2010 survey and the 2013 survey. However, in terms of the regression coefficients, the effect of the respondent's social status was greater in 2010, while that of parents was greater in 2013. Statistical tests of the interaction items show that the effect of one's social status does not differ significantly between the two waves, but the effect of parents' social status increases significantly over time. This shows that from 2010 to 2013, the influence of parents' social status on an individual's class identity has not diminished but has increased. Thus, the modernization and individualization theories are not supported by the data. 
Table 6 Change in the effect of individual and parents' social statuses on class identity over time

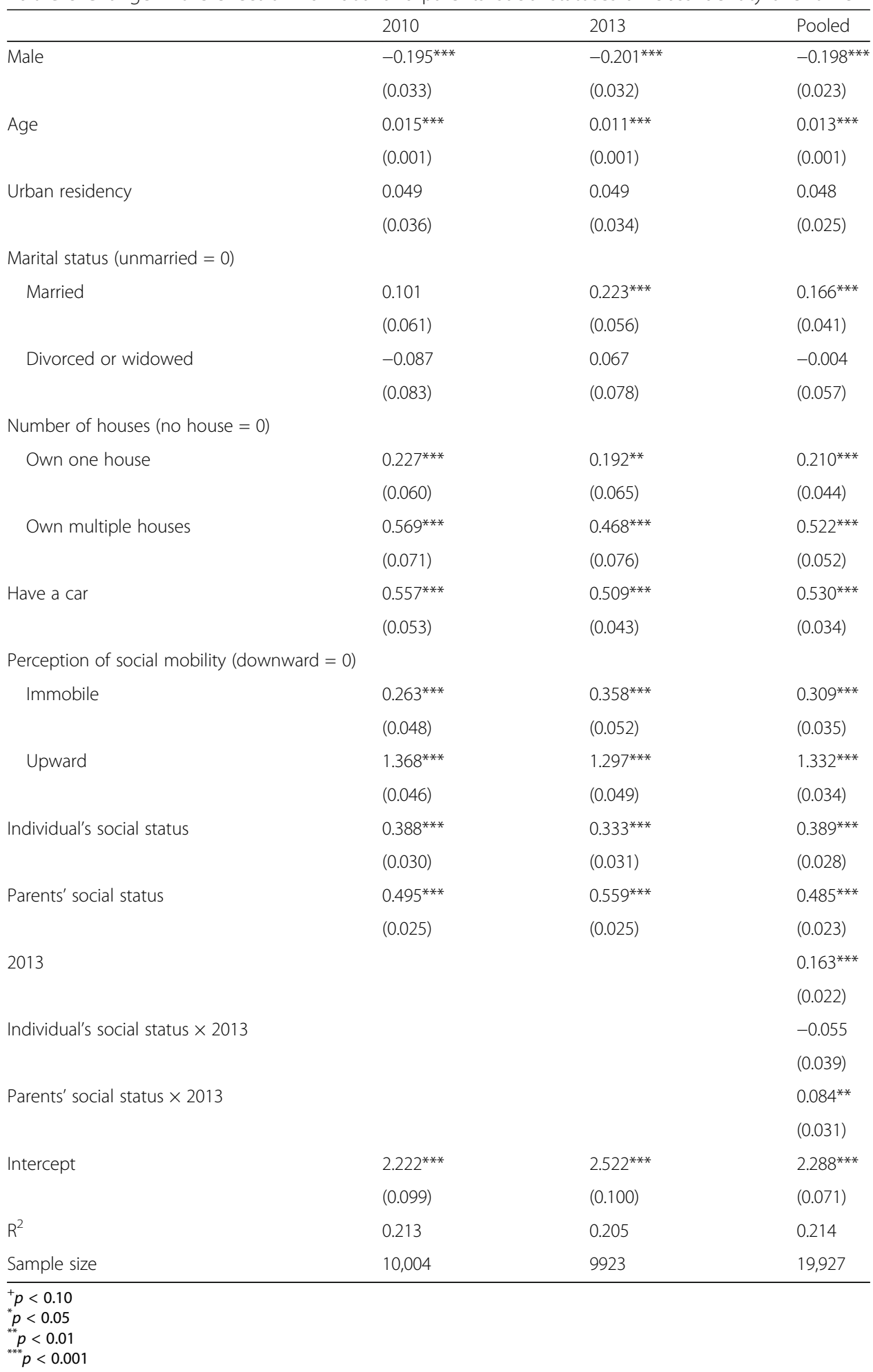

Last, the study of married people suggests that from 2010 to 2013, the impact of a spouse's social status on the subjective class identity of an individual increased significantly for both men and women, while the impact of men's social status showed a slightly downward trend (Table 7). In accordance with Davis and Robinson's concept 
Table 7 Change in the effect of individual and spouse's social statuses on class identity over time

\begin{tabular}{|c|c|c|c|c|c|c|}
\hline & \multicolumn{3}{|c|}{ Married female } & \multicolumn{3}{|c|}{$\underline{\text { Married male }}$} \\
\hline & 2010 & 2013 & Pooled & 2010 & 2013 & Pooled \\
\hline \multirow[t]{2}{*}{ Age } & $0.011^{* * *}$ & $0.009^{* * *}$ & $0.010^{* * *}$ & $0.018^{* * *}$ & $0.015^{* * *}$ & $0.016^{* * *}$ \\
\hline & $(0.002)$ & $(0.002)$ & $(0.001)$ & $(0.002)$ & $(0.002)$ & $(0.001)$ \\
\hline \multirow[t]{2}{*}{ Urban residency } & -0.037 & -0.080 & -0.061 & -0.015 & -0.002 & -0.008 \\
\hline & $(0.058)$ & $(0.055)$ & $(0.040)$ & $(0.061)$ & $(0.056)$ & $(0.041)$ \\
\hline \multicolumn{7}{|l|}{ Number of houses (no house $=0$ ) } \\
\hline \multirow[t]{2}{*}{ Own one house } & $0.228^{*}$ & $0.351^{* *}$ & $0.278^{* * *}$ & $0.412^{* * *}$ & 0.108 & $0.255^{* * *}$ \\
\hline & $(0.102)$ & $(0.120)$ & $(0.077)$ & $(0.109)$ & $(0.108)$ & $(0.076)$ \\
\hline \multirow[t]{2}{*}{ Own multiple houses } & $0.577^{* * *}$ & $0.602^{* * *}$ & $0.579 * * *$ & $0.745^{* * *}$ & $0.404^{* *}$ & $0.569^{* * *}$ \\
\hline & $(0.119)$ & $(0.134)$ & $(0.088)$ & $(0.125)$ & $(0.124)$ & $(0.088)$ \\
\hline \multirow[t]{2}{*}{ Have a car } & $0.406^{* * *}$ & $0.416^{* * *}$ & $0.411^{* * *}$ & $0.536^{* * *}$ & $0.579^{* * *}$ & $0.565^{* * *}$ \\
\hline & $(0.090)$ & $(0.069)$ & $(0.055)$ & $(0.085)$ & $(0.069)$ & $(0.053)$ \\
\hline \multicolumn{7}{|c|}{ Perception of social mobility (downward $=0$ ) } \\
\hline \multirow[t]{2}{*}{ Immobile } & $0.231^{* *}$ & $0.406^{* * *}$ & $0.312^{* * *}$ & $0.302^{* * *}$ & $0.270^{* *}$ & $0.288^{* * *}$ \\
\hline & $(0.082)$ & $(0.087)$ & $(0.060)$ & $(0.080)$ & $(0.084)$ & $(0.058)$ \\
\hline \multirow[t]{2}{*}{ Upward } & $1.352^{* * *}$ & $1.271^{* * *}$ & $1.308^{* * *}$ & $1.335^{* * *}$ & $1.241^{* * *}$ & $1.286^{* * *}$ \\
\hline & $(0.078)$ & $(0.082)$ & $(0.056)$ & $(0.078)$ & $(0.079)$ & $(0.055)$ \\
\hline \multirow[t]{2}{*}{ Parent's social status } & $0.479^{* * *}$ & $0.443^{* * *}$ & $0.463^{* * *}$ & $0.470^{* * *}$ & $0.516^{* * *}$ & $0.493^{* * *}$ \\
\hline & $(0.041)$ & $(0.041)$ & $(0.029)$ & $(0.041)$ & $(0.040)$ & $(0.029)$ \\
\hline \multirow[t]{2}{*}{ Individual's social status } & 0.091 & 0.085 & 0.095 & $0.532^{* * *}$ & $0.386^{* * *}$ & $0.525^{* * *}$ \\
\hline & $(0.054)$ & $(0.054)$ & $(0.051)$ & $(0.052)$ & $(0.054)$ & $(0.051)$ \\
\hline \multirow[t]{2}{*}{ Spouse's social status } & $0.326^{* * *}$ & $0.492^{* * *}$ & $0.336^{* * *}$ & 0.014 & $0.099^{*}$ & -0.012 \\
\hline & $(0.050)$ & $(0.051)$ & $(0.048)$ & $(0.049)$ & $(0.048)$ & $(0.047)$ \\
\hline \multirow[t]{2}{*}{2013} & & & $0.141^{* * *}$ & & & $0.211^{* * *}$ \\
\hline & & & $(0.040)$ & & & $(0.043)$ \\
\hline \multirow[t]{2}{*}{ Individual's social status $\times 2013$} & & & -0.015 & & & $-0.127+$ \\
\hline & & & $(0.071)$ & & & $(0.071)$ \\
\hline \multirow[t]{2}{*}{ Spouse's social status $\times 2013$} & & & $0.147^{*}$ & & & $0.132^{*}$ \\
\hline & & & $(0.068)$ & & & $(0.063)$ \\
\hline \multirow[t]{2}{*}{ Intercept } & $2.475^{* * *}$ & $2.604^{* * *}$ & $2.485^{* * *}$ & $2.389^{* * *}$ & $2.389^{* * *}$ & $2.080^{* * *}$ \\
\hline & $(0.151)$ & $(0.163)$ & $(0.110)$ & $(0.079)$ & $(0.079)$ & $(0.114)$ \\
\hline$R^{2}$ & 0.198 & 0.198 & 0.202 & 0.202 & 0.202 & 0.218 \\
\hline Sample size & 3860 & 3756 & 7616 & 15,047 & 15,047 & 7431 \\
\hline
\end{tabular}

(1988), I argue that over time, the class identity of married Chinese men has changed from "independent" to "shared," while the class identity of married Chinese women has become increasingly dependent on men.

The above analysis shows that the influence of the social statuses of the individual, parents, and spouse on the subjective class identity of the Chinese population does not follow the path of modernization and individualization theory but instead returns to tradition. Therefore, the results support hypothesis 9 and reject hypothesis 8 . Classical modernization and individualization theory cannot be applied so simply to analyze the 
trend of Chinese class identity. Instead, the analysis should be based on the specific situation in China. In the concluding section that follows, I will discuss this issue in more depth.

\section{Conclusion and discussion}

In this article, I use data from the Chinese General Social Survey in 2010 and 2013 to study the factors influencing the Chinese subjective class identity and its bias. In contrast with previous studies, which have mostly focused on the social status of the respondents, this study proposes the concept of "mixed" class identity, which combines the social statuses of the respondents, their spouses, and their parents to conduct a more in-depth and comprehensive study on the formation of subjective class identity and its bias. The main findings are as follows.

First, the objective social status of the individual, spouse, and parents all influence the subjective class identity of the individual, and the social statuses of the spouse and parents is also an important factor influencing the class identity bias of the individual. The subjective class identity of Chinese is determined not only by oneself but also by the family. Unlike in Western countries, where class identity involves only the person and the spouse in a nuclear family, the Chinese family is an extended family that includes parents. This extended family tradition profoundly influences the living arrangements and intergenerational interactions of Chinese, the status and achievements that individuals can attain, as well as the way that Chinese understand themselves and perceive society inevitably shapes the way that Chinese form their own class identity. In summary, Chinese class identity is family-based, not individual-based, and so the study of Chinese class identity also needs to shift from an individual perspective to a family perspective.

Second, while in general, the social statuses of the individual, spouse, and parents all influence an individual's subjective class identity; their influence varies by the individual's age, living arrangement with parents, and marital status. Specifically, young people and those who co-reside with their parents have a stronger financial and emotional attachment to their parents, which leads them to consider their parents more when assessing their class identity. Moreover, influenced by traditional gender attitudes, the class identity of married men is mainly influenced by their own status and less by that of their spouses; in contrast, the class identity of married women is primarily determined by the social status of their husbands. The same conclusion can also be deduced from the analysis of class identity bias. These findings show that the factors influencing an individual's class identity are very complex. Future studies should take full consideration of these complexities when analyzing Chinese people's class identity.

Finally, the study found that the influence of parents and spouses' social statuses on individual class identity did not diminish over time but rather increased, so that the gradual separation of individuals from the family, as predicted by modernization and individualization theory, did not occur in China. On the one hand, this may be because Chinese family traditions or attitudes are so rigid that the attitudes of individuals do not change abruptly as a result of social development. On the other hand, many studies have also found that China's modernization process has its own characteristics, influenced by its particular cultural traditions, political system, and social structure. Therefore, it is not possible to simply follow the Western model of modernization or individualization to understand Chinese society. This is manifested in the following 
aspects. First, although China's market reform has created many opportunities for social mobility, inequalities in opportunities and outcomes due to differential family backgrounds are still prevalent ( $\mathrm{Li}$ and Zhu 2015), and it is difficult for individuals to make independent and objective judgments without the influence of their parents when evaluating their class status. Second, the expansion of the market sector due to the reform has put women at a greater disadvantage in the labor market (He and Wu 2015), and the decline of women's market status compared with men has also resulted in their psychological dependence on men. Third, Chinese society has not established a comprehensive social security system that is appropriate for the process of modernization. Families still carry irreplaceable social functions in housing, childcare, and eldercare. The continuation or even strengthening of family functions has objectively strengthened organic solidarity between generations and enhanced extended-family networks in China (Xu 2013). These three aspects suggest that the family will remain the basic unit of material and emotional support for Chinese for many years, so the "mixed" class identity proposed in this study will also continue in the future.

In the end, it is important to note the limitations of the study. First, the social statuses of the respondents themselves, their spouses, and their parents are not measured in the same way, which somewhat reduces the comparability of the relative effects among the three. Second, due to data limitations, this analysis does not include the occupational status index, a commonly used measure of the social statuses of the person and spouse. Finally, this study only examines changes in the influence of the individual, spouse, and parents' social statuses from 2010 to 2013 and does not cover a longer historical period due to data restrictions. We expect that as survey data and research tools keep improving, we will be able to test the findings of this article more comprehensively in the future.

\section{Abbreviations}

ISEl: International Socio-Economic Index; SES: Social-economic status; CGSS: Chinese General Social Survey

\section{Acknowledgements}

$\mathrm{N} / \mathrm{A}$

Author's contributions

Xu Qi designed and constructed the whole research. The author read and approved the final manuscript.

Funding

N/A

Availability of data and materials

I use data from the Chinese General Social Survey in 2010 and 2013 for this study.

Competing interests

The author has no competing interests.

Received: 1 May 2020 Accepted: 7 June 2020

Published online: 28 June 2020

References

Baxter, J. 1994. Is Husband's class enough? Class location and class identity in the United States, Sweden, Norway, and Australia. American Sociological Review 59 (2): 220-235.

Bian, F., J.R. Logan, and Y. Bian. 1998. Intergenerational relations in urban China: Proximity, contact, and help to parents. Demography 1: 115-124.

Bian, Y. 2002. Chinese social stratification and social mobility. Annual Review of Sociology 28: 91-116.

Bian, Yanjie, and Hanlong Lu. 2002. Economic reform and socioeconomic inequality: Status perceptions in Shanghai. In Market transition and social stratification: American sociologists' analyses of China, ed. Yanjie Bian. Beijing: Joint Publishing House [ln Chinese].

Blau, P.M., and O.D. Duncan. 1967. The American occupational structure. New York: Free Press. 
Chu, C.Y.C., and R. Yu. 2010. Understanding Chinese families: A comparative study of Taiwan and Southeast China. New York: Oxford University Press.

Davis, N.J., and R.V. Robinson. 1988. Class identification of men and women in the 1970s and 1980s. American Sociological Review 1: 103-112.

Dong, Yunsheng. 2007. Status inconsistency and class structuration. Jilin University Journal Social Sciences Edition 1: 151-155 [In Chinese].

Fan, Xiaoguang, and Yunsong Chen. 2015. The class identity bias of Chinese urban and rural residents. Sociological Studies 4: 143-168 [In Chinese].

Feng, Shizheng. 2011. Class identity and social stability in China's social transition. Social Sciences in Heilongjiang 3: 127-133 [In Chinese].

Ganzeboom, H.B.G., D.J. Treiman, and W.C. Ultee. 1991. Comparative intergenerational stratification research: Three generations and beyond. Annual Review of Sociology 17: 277-302.

Gao, Yong. 2013. Why has status identification declined: On the changes in the basis of status identification. Chinese Journal of Sociology 4: 83-102 [In Chinese].

Goldthorpe, J.H. 1983. Women and class analysis: In defense of the conventional view. Sociology 17 (4): 465-488.

Goode, W.J. 1963. World revolution and family patterns. New York: Free Press.

Han, Yu, and Liping Qiu. 2015. Urban residents' class status identification discordance. Journal of Social Development 1: 1-17 [In Chinese].

He, Guangye, and Xiaogang Wu. 2015. Marketization, occupational segregation, and gender earnings inequality in urban China. Sociological Studies 1: 140-165 [In Chinese].

Hodge, R.W., and D.J. Treiman. 1968. Class identification in the United States. American Journal of Sociology 73 (5): $535-547$.

Hout, M. 2008. How class works in popular conception: Most Americans identify with the class their income, occupation, and education implies for them. In Social class: How does it work? ed. Annette Lareau and Dalton Conley. New York: Russell Sage Foundation.

Kelley, J., and M.D.R. Evans. 1995. Class and class conflict in six Western nations. American Sociological Review 60 (2): $157-178$.

Lei, Kaichun. 2009. The analysis of the current situation and the reasons for white-collar new migrants' SES identification deviation. Youth Studies 4: 60-70 [In Chinese].

Li, Chunling. 2003. The social stratum consciousness of contemporary Chinese people. Social Sciences in Hunan 5: 76-79 [In Chinese].

Li, Chunling. 2010. Expansion of higher education and unequal educational opportunities: Review of the effectiveness of equalization of expanded college recruiting. Sociological Studies 3: 76-79 [In Chinese].

Li, Lulu, and Bin Zhu. 2015. Changes in the pattern of intergenerational mobility in contemporary China. Social Sciences in China 5: 40-58 [In Chinese].

Li, Qiang. 2008a. Change of social stratification in China since reform and opening-up. Social Sciences of Beijing 5: 47-60 [ln Chinese].

$\mathrm{Li}, \mathrm{Yu}$. 2007. The effect of family background in the attainment of initial social status and its change. Jiangsu Social Sciences 5 : 103-110 [In Chinese].

Li, Yu. 2008b. Trends in educational assortative marriage: 1949-2000. Chinese Journal of Population Science 3: 73-79 [In Chinese].

Li, Yu. 2011. The change of marriage matching: A perspective of social openness. Sociological Studies 4: 122-136 [In Chinese].

Liu, Xin. 2001. Class consciousness of China's urban residents during the transitional period. Sociological Studies 3: 8-17 [In Chinese].

Liu, Xin. 2002. Relative deprivation status and class cognition. Sociological Studies 1: 81-90 [In Chinese].

Logan, R.J., F. Bian, and Y. Bian. 1998. Tradition and change in the urban Chinese family: The case of living arrangements. Social Forces 76 (3): 851-882.

Lu, Fuying, and Zhaoshu Zhang. 2006. Objective stratification and subjective identity. Chinese Journal of Population Science 3: 38-43 [In Chinese].

Qi, Yaqiang and Niu, Jianlin. 2012. "The Evolution of Assortative Mating Patterns in the Process of China's Modernization." Sociological Studies (1):106 - 29. [In Chinese].

Shi, Jinqun. 2016. The evolvement of family intergenerational relationship in transition: Mechanism, logic and tension. Sociological Studies 6: 191-213 [In Chinese].

Stanworth, M. 1984. Women and class analysis: A reply to John Goldthorpe. Sociology 18 (2): 159-170

Tang, Can. 2010. A review of modernization theory and its development on family. Sociological Studies 3: 152-156 [In Chinese].

Thornton, A., and T.E. Fricke. 1987. Social change and the family comparative perspectives from the west, China, and South Asia. Social Forum 2 (4): 746-779.

Tong, Xin, and Aiyu Liu. 2015. A model of conjugal cooperation in housework for urban dual-career couples-Based on the third survey of Women's status in China. Social Sciences in China 6: 96-111 [In Chinese].

Velsor, E.V., and L. Beeghley. 1979. The process of class identification among employed married women: Replication and reanalysis. Journal of Marriage and the Family 41 (4): 771-778.

Walder, A.G., B. Li, and D.J. Treiman. 2000. Politics and life chances in a state socialist regime: Dual career paths into Chinese elite, 1949 to 1996. American Sociological Review 65 (2): 191-209.

Wang, Shaoguang. 2012. Polanyi's "great transformation" and China's great transformation. Beijing: SDX Joint Publishing Company [In Chinese].

Wang, Yuesheng. 2013. An analysis of changes in the Chinese family structure between urban and rural areas: Based on the 2010 National Census Data. Social Sciences in China 12: 60-77 [In Chinese].

Wang, Yuesheng. 2014. A study on the types of family with elderly in urban and rural China based on the sixth census data. Chinese Journal of Population Science 1: 20-32 [In Chinese].

Wright, E.O., and K.Y. Shin. 1988. Temporality and class analysis: A comparative study of the effects of class trajectory and class structure on class consciousness in Sweden and the United States. Sociological Theory 6 (1): 58-84.

Xu, Q., J. Li, and X. Yu. 2014. Continuity and change in Chinese marriage and the family. Chinese Sociological Review 47 (1): 30-56. 
Xu, Qi. 2013. The influence of Children's needs on intergenerational Coresidence. Chinese Journal of Sociology 33: 111-130 [In Chinese].

Xu, Qi. 2016. Trend, source and heterogeneity of the change of gender-role attitude in China: A case study of two indicators. Journal of Chinese Women's Studies 3: 33-43 [In Chinese].

Xu, Qi. 2017. More than upbringing: Parents' support and the effect on filial duty. Chinese Journal of Sociology 2: 216-240 [In Chinese].

Yan, Yunxiang. 2012. The individualization of Chinese society. Shanghai: Shanghai Translation Publishing House [In Chinese] Yang, Juhua, Hongjuan Li, and Ge Zhu. 2014. Changing trends in attitudes to gender roles in China from 1990 to 2010. Journal of Chinese Women's Studies 6: 28-36 [In Chinese].

Ye, Hua, and Xiaogang Wu. 2011. Fertility decline and the trend in educational gender inequality in China. Sociological Studies 5: 153-177 [In Chinese].

Yu, Jia. 2014. Gender ideology, modernization, and Women's housework time in China. Chinese Journal of Sociology 2: $166-$ 192 [In Chinese].

Zeng, Yi, and Zhenglian Wang. 2004. Family and changes of living arrangements of the elderly in China. Chinese Journal of Population Science 5: 2-8 [In Chinese].

Zhang, Yi. 2004. Chinese social status attainment: Class succession and intergenerational mobility. Sociological Studies 4: 7690 [In Chinese].

\section{Publisher's Note}

Springer Nature remains neutral with regard to jurisdictional claims in published maps and institutional affiliations.

Submit your manuscript to a SpringerOpen ${ }^{\circ}$ journal and benefit from:

- Convenient online submission

- Rigorous peer review

- Open access: articles freely available online

High visibility within the field

- Retaining the copyright to your article

Submit your next manuscript at $>$ springeropen.com 